\title{
Somos tierra, semilla, rebeldía: mujeres, tierra y territorio en América Latina, Claudia Korol, 2016
}

$\mathrm{S}$ omos tierras, semilla, rebeldía: Mujeres, tierras y territorio en América Latina es un libro que aborda el problema que enfrentan las mujeres de sectores rurales en América Latina para acceder a la tierra, resultado del sistema patriarcal, capitalista y colonial de dominación, que ha implantado formas culturales de invisibilización hacia las mujeres a partir de la división social y sexual del trabajo. La autora Claudia Korol nos presenta desde una mirada histórica acerca del control y acceso de la tierra, siendo el campesinado el menor beneficiario, y aún menos, la mujer campesina.

Dentro de su relato presenta interesantes interrogantes que nos permiten cuestionar las formas económicas, políticas y culturales del sistema patriarcal, capitalista y colonial, ya que nos expresa el rol que cumple la mujer indígena y campesina en la sociedad, siendo un sujeto que vela por la reproducción de la vida, en el cuidado de los pueblos, comunidades y personas, pues, en ella se deposita la subsistencia de la humanidad, garantizando la soberanía alimentaria y el cuidado de la naturaleza. Por tal razón, la autora se pregunta por la continua situación de desigualdad social y política en que se encuentran las mujeres campesinas e indígenas, sembrando resistencia a tal hecho, y expresando el acceso de las mujeres a la tierra como un factor fundamental para garantizar la propia soberanía, autonomía y derechos sobre las mujeres, lo que viene acompañado a la erradicación de la pobreza y el hambre de los pueblos.

Para el desarrollo de esta discusión se ha planteado analizar el problema del acceso a la tierra de las mujeres como uno de los fundamentos materiales y culturales del sistema patriarcal, capitalista y colonial de dominación, y de establecer estas implicancias en el entendimiento de la situación de millones de mujeres en el continente latinoamericano, ya que, según datos de la FAO, solamente "el 30\% de mujeres rurales poseen tierras agrícolas, y no tienen acceso a los medios de producción" (Korol, 2016: 10).

En el cumplimiento de tales objetivos se generaron enfoques que permitieron la realización de la investigación, construidos para generar una visión amplia del contexto, a través, principalmente, del diálogo con las organizaciones del mundo indígena, campesino, negro, feminista y popular.

Mediante una mirada histórica a los procesos sociales del mundo indígena, se pudo visualizar los fenómenos coyunturales para entender el establecimiento de un sistema de dominación. Esto llevó a indagar por el concepto de cultura e identidad de los estudios de género desde nociones eurocéntricas y occidentales, sirviendo de guía para comprender el sistema colonial y patriarcal que se instaló en territorios de los pueblos originarios. 
Desde la voz de la cultura campesina y sus organizaciones populares se conoció el significado que tiene la tierra para esta cultura, y cuáles han sido las significaciones de la reforma agraria en los diferentes grupos y clases sociales, sirviendo como herramienta para entender las concepciones culturales, lo que aportó para pensar sobre la situación de desigualdad social y política de la mujer.

Con estas interrogantes se dialogó con las organizaciones campesinas, movimientos de las mujeres que integran la Vía Campesina Internacional (LVCI), y la Coordinadora Latinoamericana de Organizaciones del Campo (CLOC), que han pensado en un feminismo campesino y popular para analizar "el lugar de las mujeres en la distribución de tierras, en el acceso a la propiedad, y en el cambio de los roles sociales establecidos por la cultura patriarcal para la vida social en el campo" (Korol, 2016: 18).

Para interactuar en este feminismo campesino y popular se ha cuestionado los puntos ideológicos del feminismo occidental, el cual ha pensado la situación de la mujer desde el promover un mayor acceso de las mujeres a la propiedad de la tierra, en la búsqueda de integrar a las mujeres a las lógicas del agronegocio. Esto colaboró para ubicarse contextualmente desde los sectores populares, haciendo reales movimientos feministas campesinos, y no ideas flotantes de discurso.

En tanto, desde las corrientes del feminismo comunitario, indígena, campesino y popular en que se direccionó este discurso se pudo ofrecer un análisis contextual, enfocándose en la realidad social para comprender los cambios sociales, culturales, políticos y económicos que ha vivido el sector popular. Pero sobre todo, a partir de esta corriente se logró entender las significaciones culturales que estos procesos han dado a la vida social del mundo campesino e indígena, interpeladas de luchas políticas.

De igual forma, el ecofeminismo aportó para tomar una posición de lucha y de cambio, para frenar la situación de desigualdad social de las mujeres indígenas y campesinas, acompañada de un beneficio global, ya que, fraccionar el problema del acceso de las mujeres a la tierra mejoraría la productividad agrícola, al ser ellas responsables y poseedoras de sus propias tierras agrícolas.

A lo largo del texto se puede apreciar una observancia a cada planteamiento que se ofrece, junto con la metodología que se esboza, logrando un análisis crítico en medio de un relato armónico. Sin embargo, es necesaria una profundización del concepto de cultura e identidad que se plantea en la introducción para entender cómo estos conceptos se instalan en las subjetividades de los individuos para construir una colonialidad.

Finalmente, parece preciso mencionar la frase con la que la autora concluye su análisis, "cuidar la vida, cuidar las semillas, cuidar la memoria, cuidar los territorios, implica también, y como condición, cuidar a las cuidadoras" (Korol, 2016: 178), permitiendo comprender y luchar por la necesidad de derecho de las mujeres campesinas e indígenas a la posesión de la tierra, para lograr no solamente una igualdad social y política de las mujeres, sino también, un derecho a la naturaleza, a su cuidado y bienestar, beneficiando a la sociedad global, a través de recuperación de la sabiduría de las mujeres sobre el trato justo de las tierras. 